\title{
EVALUACIÓN BIOLÓGICA DE PROTEÍNA, VITAMINAS, MINERALES Y AMINOÁCIDOS DEL ALGA COMESTIBLE Ulva lactuca "LECHUGA DE MAR" DEL LITORAL PERUANO
}

\author{
Liliana Sumarriva Bustinza ${ }^{* a}$ Américo Castro Luna ${ }^{\mathrm{b}}$, \\ Alejandrina Sotelo Méndez ${ }^{\mathrm{c}}$, Nadia Chávez Sumarriva ${ }^{\mathrm{b}}$.
}

\begin{abstract}
RESUMEN
Las algas han sido parte de la dieta humana durante cientos de años. En el Perú, la evidencia arqueológica más antigua del consumo de algas se encuentra a lo largo de la costa peruana e.g. en Pampa (ca. 2500 a. C.), en Playa Hermosa (2500-2275 a. C.), además se encontraron pequeñas algas marinas en las momias de la cultura Paracas lo que indica que las algas marinas podrían haber sido empleadas por los antiguos peruanos para complementar sus dietas. En el Perú, el consumo de algas está en auge, provocado por el creciente interés de los consumidores por alimentos con alto valor nutritivo.

El objetivo de esta investigación fue determinar la calidad de proteína, vitaminas, minerales y aminoácidos del alga de consumo humano Ulva lactuca. El análisis de proteínas se hizo por el método de Weende, el de vitaminas y minerales por método de la AOAC, los aminoácidos se determinaron por el método de intercambio iónico, utilizando un analizador de aminoácidos, la evaluación biológica de la calidad de proteínas, mediante la Razón de Eficiencia Proteica (PER), y la Razón Neta de Proteína (NPR). Los resultados fueron: proteína $27,38 \%$,fibra $3,37 \%$, grasa $0,48 \%$, etc.; en vitaminas: $0,257 \mathrm{mg} / 100 \mathrm{~g}$ tiamina, 0,05 $\mathrm{mg} / 100 \mathrm{~g}$ riboflavina, $0,3 \mathrm{mg} / 100 \mathrm{~g}$ caroteno; minerales: $2,1 \mu \mathrm{g} / \mathrm{g}$ de cobre, $25,6 \mu \mathrm{g} / \mathrm{g}$ de zinc, $21,81 \mathrm{mg} / \mathrm{g}$ de calcio, $15,14 \mathrm{mg} / \mathrm{g}$ de magnesio; en aminoácidos: $1,32 \%$ de lisina, $0,2 \%$ de histidina, 1,54 \% de arginina, 2,05\% de ácido aspártico. En calidad de proteína se encontró 1,16 con la prueba PER y 2,2 con NPR.

Se concluye que el alga Ulva lactuca, presenta proteína, vitaminas, minerales y aminoácidos esenciales, potencialmente utilizable en la industria alimentaria; además de ser un alimento saludable para la nutrición humana y animal.
\end{abstract}

Palabras clave: Ulva lactuca, evaluación biológica, PER, NPR.

\footnotetext{
a Departamento de Química, Facultad de Ciencias, Universidad Nacional de Educación "Enrique Guzmán y Valle”. Av. Enrique Guzmán y Valle s/n, La Cantuta - Chosica, Perú. Email: 1ilisumarriva@gmail.com

b. Instituto de Investigación en Ciencias Farmacéuticas y Recursos Naturales “Juan de Dios Guevara" de la Facultad de Farmacia y Bioquímica, Universidad Nacional Mayor de San Marcos.

c. Departamento de Nutrición, Facultad de Zootecnia, Universidad Nacional Agraria La Molina.
} 


\title{
BIOLOGICAL EVALUATION OF PROTEIN, VITAMINS, MINERALS AND AMINO ACIDS OF EDIBLE ALGAE Ulva lactuca "SEA LETTUCE" FROM THE PERUVIAN LITTORAL.
}

\begin{abstract}
Algae had been part of the human diet for hundreds of years. In Peru, the oldest archaeological evidence of algae was found along the Peruvian coast e.g. in Pampa (ca. 2500 B.C.), in Playa Hermosa (2500-2275 B.C.), small marine algae were also found in the mummies of the Paracas culture, which indicates that marine algae could have been used by the ancient Peruvians to supplement their diets. In Peru, the consumption of algae is increasing caused by the growing interest of consumers for foods with high nutritional value.

The aim of this research was to determine the protein quality, vitamins, minerals and amino acids of the algae Ulva lactuca; which is used for human consumption. Protein analysis was made by the Weende method, vitamins and minerals by the AOAC method, the amino acids were determined by the ion exchange method, using an amino acid analyzer, the biological evaluation of the protein quality by the Protein Efficiency Ratio (PER), and the Net Protein Ratio (NPR). The results were: protein $27,38 \%$,fiber 3,37 \%, fat 0,48 \%; vitamins: 0,257 $\mathrm{mg} / 100 \mathrm{~g}$ thiamine, $0,05 \mathrm{mg} / \mathrm{g}$ riboflavin, $0,3 \mathrm{mg} / 100 \mathrm{~g}$ carotene; minerals: $2,1 \mu \mathrm{g} / \mathrm{g}$ of copper, $25,6 \mu \mathrm{g} / \mathrm{g}$ of zinc, $21,81 \mathrm{mg} / \mathrm{g}$ of calcium, $15,14 \mathrm{mg} / \mathrm{g}$ of magnesium; amino acids: $1,32 \%$ of lysine, $0,2 \%$ of histidine, $1,54 \%$ of arginine, $2,05 \%$ of aspartic acid, etc. In protein quality, 1,16 was found with the PER test and 2,2 with NPR test.

It is concluded that Ulva lactuca algae present proteins, vitamins and minerals which could be used in the food industry; it is also a health food for human and animal nutrition.
\end{abstract}

Key words: Ulva lactuca, biological evaluation, PER, NPR.

\section{INTRODUCCIÓN}

Las algas han sido parte de la dieta humana durante cientos de años. En el Perú, la evidencia arqueológica más antigua del consumo de algas se encuentra a lo largo de la costa peruana e.g. en Pampa (ca. 2500 a. C. $)^{1}$; en Playa Hermosa (2500-2275 a. C. $)^{2}$; en Concha (22751900 a. C. $)^{2}$; en Aspero (Caral) (2275-1850 a. C.)3; en Gaviota (1900-1750 a. C.) $)^{2}$ y en Ancón (1400-1300 a. C. $)^{2}$. Patterson y Moseley ${ }^{2}$ creen que estos hallazgos indican que las algas marinas eran empleadas por los antiguos peruanos para complementar sus dietas ${ }^{4}$.

Existe más evidencia que indica la presencia de algas marinas en el antiguo Perú e.g. la base de los templos de Las Haldas (ca.1650 a. C.), contenía grandes cantidades de algas marinas y $\operatorname{mariscos}{ }^{5}$, además se encontraron pequeñas algas marinas en las momias de la cultura Paracas $^{6}$, también se encontraron representaciones de algas marinas en huacos de la cultura $\mathrm{Nazca}^{4,7}$. 
En la actualidad, son miles las especies de algas conocidas y distribuidas a lo largo de todo el planeta, ofreciendo un gran número de usos y aplicaciones. Un reciente informe de la FAO indica que en 2014 se cultivaron alrededor de 28,5 millones de toneladas de algas marinas y de otro tipo para el consumo directo o para la ulterior elaboración de alimentos (tradicionalmente en Japón, la República de Corea y China) o para utilizarlas como fertilizantes y con fines farmacéuticos o cosméticos, entre otros ${ }^{8}$. Además, las algas marinas están siendo muy utilizadas como alimento para animales (e.g. bovinos y aves) ${ }^{8,9} \mathrm{y}$ también se usan en medicina, por ejemplo, para tratar la carencia de yodo y como vermífugo ${ }^{8}$.

En el Perú el consumo de algas está en auge, provocado por el creciente interés de los consumidores por alimentos con alto valor nutritivo. En este sentido, el empleo de algas en el desarrollo de nuevos suplementos alimenticios es interesante, ya que estas pueden aportar nutrientes esenciales.

El objetivo de este trabajo fue evaluar los nutrientes del alga Ulva lactuca o conocida comúnmente como "lechuga de mar" la cual es una especie de alga muy común en el Perú y según los resultados, considerarlas o no, como alternativas para la alimentación humana y animal.

\section{PARTE EXPERIMENTAL}

La investigación y los análisis se realizaron en los Laboratorios de Análisis Químico y Análisis Biológico del Departamento de Nutrición, Facultad de Zootecnia de la Universidad Nacional Agraria La Molina y el análisis de aminoácidos en el Centro Nacional de Alimentación y Nutrición (CENAN).

\section{Toma de muestras}

La especie de alga Ulva lactuca se recolectó en la bahía de Ancón, Lima, Perú (coordenadas geográficas: $11^{\circ} 45^{\prime}$ de latitud Sur y $77^{\circ} 15^{\prime}$ de longitud Oeste); además, se usó la Tabla de Mareas de la Dirección de Hidrografía y Navegación de la Marina de Guerra del Perú con el objetivo de obtener una mayor cantidad de Ulva lactuca.

\section{Tratamiento de las muestras}

Las algas fueron lavadas cuidadosamente para eliminar impurezas, seguidamente fueron parcialmente deshidratadas por el sol con una energía solar promedio de $6 \mathrm{~kW} \mathrm{~h} / \mathrm{m}^{2}$ $(\text { SENAMHI })^{10}$ con una humedad promedio de $82 \%$, luego se colocó en una estufa de secado universal (memmert) a $60^{\circ} \mathrm{C}$, después se pulverizaron las algas en un molino Thomas Model 3 (WileyMill) equipado con una malla $\mathrm{N}^{\circ} 40$. El resultado fue un polvo fino, a partir del cual se realizaron los análisis respectivos.

\section{Análisis químico}

Para determinar la cantidad de proteína, fibra, grasa, nifex y ceniza se utilizó el método de análisis proximal de Weende ${ }^{11}$. Para determinar la cantidad de vitaminas y minerales se 
utilizó los métodos descritos por la Asociación Oficial de Químicos Agrícolas (AOAC) ${ }^{12}$. Los aminoácidos se determinaron por el método de intercambio iónico, utilizando un analizador de aminoácidos (Beckman-modelo 120).

\section{Análisis biológicos}

Los análisis biológicos para determinar la calidad de la proteína de la Ulva lactuca fueron: Razón de Eficiencia Proteica (PER) y Razón Neta de Proteína (NPR). Ambos métodos miden la respuesta del animal (i.e. ganancia de peso en relación a la ingesta de proteína en una dieta ajustada al $10 \%$ de proteína). El PER se describe como un bioensayo de un solo punto, dado que mide la respuesta a un solo nivel de proteína, el NPR es un bioensayo de dos puntos, pues mide la respuesta a dos niveles de proteína (10\% de la proteína prueba y $0 \%$ de proteína i.e. una dieta libre de proteína). Para la conducción de este experimento se siguió el método descrito por la National Academic of Sciences ${ }^{13}$, para la determinación del PER, y para el NPR se utilizó ratas albinas machos de raza Holtzman de 21 a 23 días de edad y con un peso inicial de 40-50 g, las que fueron distribuidas al azar en jaulas individuales, provistas de comederos de vidrio $^{14}$. La temperatura promedio del laboratorio durante los análisis fue de $21^{\circ} \mathrm{C}$. Las raciones se prepararon en base al análisis proximal de la Ulva lactuca y de la caseína, utilizando el nivel de proteína total de $10 \%$ y $3800 \mathrm{kcal} / \mathrm{kg}$, las cuales constituyen raciones isocalóricas e isoproteicas; las raciones preparadas fueron mantenidas al ambiente en invierno y en refrigeración en verano, para evitar la oxidación de las grasas, teniendo como dieta control a la caseína. El periodo experimental duró cuatro semanas (28 días) para el PER y dos semanas (14 días) para el NPR, cada séptimo día se registró el consumo de alimentos y cambio de peso de las ratas albinas; el alimento fue suministrado a libre consumo. Al concluir el tiempo del bioensayo se determinó el valor del PER exp, PER $_{\text {ajustado }} \mathrm{y}$ NPR en base a las siguientes fórmulas:

$\mathrm{R}=$ Resistencia externa (Ohmios), siendo la escogida 5,6 KOhms

$\mathrm{A}=$ Área del electrodo $\left(\mathrm{m}^{2}\right)$, teniendo cada uno de estos $1 \mathrm{~cm}^{2}$

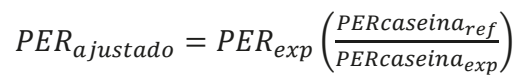

Donde:

PERexp : Valor PER obtenido en el bioensayo

PERcaseinaref : Valor de la caseína de referencia $=2,5$

PERcaseinaexp : Valor PER de la caseína obtenido en el bioensayo

$$
N P R=\frac{\text { Ganancia peso del grupo experimental }(g)+\text { pérdida de peso del grupo no proteico }(g)}{\text { Proteína Consumida }(g)}
$$




\section{Estadística}

Se tomó el diseño de Bloques Completos al Azar, el cual se aplica cuando el material es heterogéneo, las unidades experimentales homogéneas se agrupan formando grupos homogéneos llamados bloques. Las ratas albinas se han agrupado en bloques de acuerdo al peso en orden descendente de éstas, constituyendo el bloque I con las ratas de mayor peso. En la ejecución del experimento, las ratas de cada bloque han sido tratadas en igual forma, a fin de mantener la relativa homogeneidad dentro del bloque; teniendo número igual de repeticiones para todos los tratamientos.

Para su evaluación se tomó la prueba de significación de Duncan, por dar mayor límite de significación (Mayor Exigencia) en las comparaciones de las raciones.

\section{RESULTADOS Y DISCUSIÓN}

Las algas marinas son conocidas por ser una excelente fuente de vitaminas y minerales, especialmente sodio y iodo, debido a su alto contenido de polisacáridos. Los resultados de los análisis (proximal, vitaminas y minerales) de la Ulva lactuca recolectada en Ancón, Perú se muestran en las siguientes tablas con resultados en base seca (tabla 1, tabla 2, tabla 3 y tabla 4).

Tabla 1. Composición proximal de la Ulva lactuca

\begin{tabular}{cc}
\hline Parámetro & $\%$ \\
\hline Proteína & 27,38 \\
Fibra & 3,37 \\
Grasa & 0,48 \\
Nifex & 44,70 \\
Ceniza & 24,07 \\
\hline Energía & $3408,8 \mathrm{cal} / \mathrm{g}$ \\
\hline
\end{tabular}

Tabla 2. Contenido de vitaminas en la Ulva lactuca

\begin{tabular}{cc}
\hline Vitamina & $\mathrm{mg} / 100 \mathrm{~g}$ \\
\hline Tiamina & 0,257 \\
Riboflavina & 0,05 \\
Carotenos & 0,3 \\
Niacina & 0,98 \\
\hline
\end{tabular}


Tabla 3. Contenido de minerales en la Ulva lactuca

\begin{tabular}{cc}
\hline Minerales & $\mu \mathrm{g} / \mathrm{g}$ \\
\hline Cobre & 2,1 \\
Zinc & 25,6 \\
\hline Minerales & $\mathrm{mg} / \mathrm{g}$ \\
\hline Potasio & 15,68 \\
Calcio & 21,81 \\
Magnesio & 15,14 \\
Sodio & 1,42 \\
Fósforo & 6,31 \\
\hline
\end{tabular}

Tabla 4. ntenido de aminoácidos en la Ulva lactuca

\begin{tabular}{cc}
\hline Aminoácido & $\%$ \\
\hline Lisina & 1,32 \\
Histidina & 0,20 \\
Arginina & 1,54 \\
Acido aspártico & 2,05 \\
Treonina & 1,21 \\
Serina & 1,20 \\
Acido glutámico & 2,97 \\
Prolina & 0,28 \\
Glicina & 1,32 \\
Alanina & 3,19 \\
Valina & 1,35 \\
Metionina & 0,36 \\
Isoleucina & 0,74 \\
Leucina & 1,53 \\
Tirosina & 0,21 \\
Fenilalanina & 1,20 \\
\hline
\end{tabular}

Los resultados de la composición proximal de la Ulva lactuca (tabla 1) indican que el nifex (carbohidratos) y la ceniza (minerales) son los componentes químicos más abundantes de este organismo. 
El porcentaje de proteína en la Ulva lactuca encontrado fue de 27,38 \%, otros autores encontraron valores de proteína en la Ulva lactuca en un rango entre 7-27,2\% ${ }^{15-18}$. La tabla 5 nos muestra la comparación de los valores de proteína en la Ulva lactuca determinado por otros investigadores en diferentes partes del mundo, se puede apreciar que la Ulva lactuca con los mayores valores de proteína se encuentran en la costa norte de Chile y en Ancón, Perú.

Tabla 5. Comparación del porcentaje de proteína en la Ulva lactuca con los valores encontrados por otros investigadores.

\begin{tabular}{cccc}
\hline Alga & Proteína \% & Lugar de Recolección & Referencia \\
\hline Ulva lactuca & $7,06 \%$ & Tung Ping Chau, Hong Kong & 15 \\
Ulva lactuca & $8,46 \%$ & Monastir, Túnez & 16 \\
Ulva lactuca & $10,7 \%$ & La Paz, México & 17 \\
Ulva lactuca & $27,2 \%$ & Costa Norte de Chile & 18 \\
Ulva lactuca & $27,38 \%$ & Ancón, Perú & Nuestro Estudio \\
\hline
\end{tabular}

Para determinar el PER $_{\text {exp }}$ y el NPR se utilizó los valores promedios de los pesos iniciales de las ratas y el peso ganado al termino del bioensayo, los resultados se muestran en la tabla 6 y tabla 7.

Tabla 6. Razón de eficiencia proteica

\begin{tabular}{cccc}
\hline Muestra & Proteína consumida (g) & Ganancia peso $(\mathrm{g})$ & PER $_{\exp }$ \\
\hline Caseína & 26,99 & 60,4 & 2,24 \\
Ulva lactuca & 19,39 & 20,13 & 1,04 \\
\hline a= Tiempo del bioensayo (28 días) & &
\end{tabular}

Tabla 7. Relación neta de proteína

\begin{tabular}{cccc}
\hline Muestra & Proteína consumida $^{\mathrm{a}}(\mathrm{g})$ & Ganancia peso $^{\mathrm{a}}(\mathrm{g})$ & $\mathrm{NPR}^{\mathrm{a}, \mathrm{b}}$ \\
\hline Caseína & 12,47 & 30,22 & 3,34 \\
Ulva lactuca & 9,48 & 9,38 & 2,2 \\
\hline $\mathrm{a}=$ Tiempo del bioensayo (14 días) & \\
$\mathrm{b}=$ Disminución de peso del grupo no proteico a los 14 días (11,37 g)
\end{tabular}

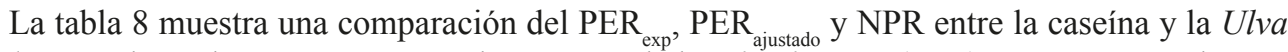
lactuca, la cual nos muestra que el PER ajustado de la Ulva lactuca $(1,16)$ es menor que el $50 \%$ del valor encontrado para el estándar de la caseína $(2,5)$ lo que nos indica que la Ulva lactuca no es óptimo como única fuente de proteína para la alimentación humana i.e. su proteína no alcanzaría ni siquiera para los niveles de mantenimiento. 
Tabla 8. Evaluación biológica de la proteína

\begin{tabular}{lccccc}
\hline \multicolumn{1}{c}{ Muestra } & $\begin{array}{c}\text { Proteína } \\
\%\end{array}$ & PER $_{\exp }$ & \multicolumn{2}{c}{ PER } & NPR \\
& $\%$ & & (ajustado) & $\%$ & \\
\hline Caseína & 84,75 & 2,24 & 2,50 & 100,0 & 3,34 \\
Ulva lactuca & 27,38 & 1,04 & 1,16 & 46,4 & 2,20 \\
\hline
\end{tabular}

\section{CONCLUSIONES}

De acuerdo a los resultados obtenidos la Ulva lactuca (lechuga de mar) recolectada en Ancón, Perú presenta valores altos de proteína en comparación a la Ulva lactuca recolectada en otras partes del mundo (e.g. Hong Kong, Túnez, México); la razón de eficiencia proteica (PER) obtenida fue menor que el $50 \%$ del valor obtenido para el estándar de caseína, lo que indica que la Ulva lactuca no es óptima como única fuente de proteína para la alimentación humana, sin embargo presenta altos valores de cenizas (minerales), altos valores de carbohidratos (nifex), bajo contenido de grasa y niveles relativamente altos de aminoácidos esenciales, lo que la convierte en un alimento potencialmente utilizable en la industria alimentaria; además de ser un alimento saludable para la nutrición humana y animal.

\section{REFERENCIAS BIBLIOGRÁFICAS}

1. Moseley ME. The maritime foundations of Andean civilization. Menlo Park, CA: Cummings Pub. Co.; 1974.

2. Patterson TC, Moseley ME. Late preceramic and early ceramic cultures of the central coast of Peru. Nawpa Pacha.1968; 6:115-33.

3. Moseley ME, Willey GR. Aspero, Peru: A Reexamination of the Site and Its Implications. Am Antiq. 1973;38(4):452-68.

4. Kiple KF, Ornelas KC, editors. The Cambridge World History of Food. Cambridge: Cambridge University Press; 2000.

5. Matsuzawa T, Shimada I. The Formative Site of Las Haldas, Peru: Architecture, Chronology, and Economy. Am Antiq. 1978;43(4):652-73.

6. Yacovleff E, Muelle JC. Un fardo funerario de Paracas. Revista Museo Nacional. 1934; 3:63-153.

7. Yacovleff E, Herrera FL. El mundo vegetal de los antiguos peruanos. Revista Museo Nacional. 1934; 3:241-322.

8. FAO. El estado mundial de la pesca y la acuicultura 2016. Contribución a la seguridad alimentaria y la nutrición para todos. Roma: FAO; 2016.

9. Becker EW. Micro-algae as a source of protein. Biotechnol Adv. 2007;25(2):207-10.

10. Senamhi. Atlas de energia solar del Peru [Internet]. Peru: 2003 [Citado Junio 2018]. Disponible en: http://dger.minem.gob.pe/atlassolar/ATLAS_SOLAR.pdf.

11. FAO. Analisis Proximales [Internet]. 2018 [Citado Junio 2018]. Disponible en:http:// www.fao.org/docrep/field/003/AB489S/AB489S03.htm. 
12. AOAC International. Official Methods of Analysis of AOAC International. 19th ed. Gaithersburg, MD, USA: AOAC International; 2012.

13. Campbell JA. Method for determination of PER \& NPR. Evaluation of protein quality. Washington, D.C.: National Academy of Sciences - National Research Council. Publ. 1100; 1963. P. 31-2.

14. Bender AE, Doell BH. Biological evaluation of proteins: a new aspect. Br J Nut. 1957;11(2):140-8.

15. Wong KH, Cheung PCK. Nutritional evaluation of some subtropical red and green seaweeds: Part I — proximate composition, amino acid profiles and some physicochemical properties. Food Chem. 2000;71(4):475-82.

16. Yaich H, Garna H, Besbes S, Paquot M, Blecker C, Attia H. Chemical composition and functional properties of Ulva lactuca seaweed collected in Tunisia. Food Chem. 2011;128(4):895-901.

17. Castro-Gonzales MI, Pérez-Gil F, Pérez-Estrella S, Carillo-Domínguez SD. Chemical composition of the green alga Ulva lactuca. Ciencas Marinas. 1996;22:205-13.

18. Ortiz J, Romero N, Robert P, Araya J, López-Hernández J, Bozzo C, et al. Dietary fiber, amino acid, fatty acid and tocopherol contents of the edible seaweeds Ulva lactuca and Durvillaea antarctica. Food Chem. 2006;99(1):98-104. 